\title{
Future transport systems: long-term visions and socio-technical transitions
}

\author{
Heidi Auvinen • Anu Tuominen
}

Received: 19 March 2013 / Accepted: 17 March 2014 / Published online: 1 April 2014

(C) The Author(s) 2014. This article is published with open access at SpringerLink.com

\begin{abstract}
Long-term, system-level foresight is needed when grand challenges are addressed in the transport sector. This paper explores how socio-technical transitions can be anticipated and taken into account in strategic transport planning. Techniques to integrate long-term foresight and understanding of socio-technical change in the transport system to support long-term transport policy targets are introduced. The proposed approach extends and combines transport system vision building to analysis of system-level changes on a three-level framework. It presents a novel, policy relevant application in the field of socio-technical transitions. The case is demonstrated with a vision of a safe and secure Finnish transport system in 2100 . First, a consistent transport system vision was created with transport experts and authorities using a structured vision building process. Second, key topics involved in the transition from the existing socio-technical system to the envisioned future were analysed using the three-level framework. The demonstration proved successful, and it has contributed to the understanding of importance of the shared long-term perspective in transport system decision-making and strategic planning. It has also generated wider discussion on transport system visions, desired futures paths as well as measures and changes required among the Finnish transport systems stakeholders.
\end{abstract}

Keywords Transport system · Foresight · Vision · Socio-technical change

\author{
H. Auvinen $(\bowtie) \cdot$ A. Tuominen \\ VTT Technical Research Centre of Finland, P.O. Box 1000, \\ 02044, VTT Espoo, Finland \\ e-mail: heidi.auvinen@vtt.fi \\ A. Tuominen \\ e-mail: anu.tuominen@vtt.fi
}

\section{Introduction}

Global warming, energy supply, urbanisation, global markets, scarcity of financial resources, security issues, aging population as well as digitalization of our environment are grand challenges, which we need to consider carefully as we make strategic plans for future transport systems. Potential measures and innovations to tackle the grand challenges are often systemic, resulting in system innovation or transition, in other words a shift from one socio-technical system to another. Such co-evolution processes involve not only technological changes but also changes in e.g. social, cultural, economic or legal dimensions. Uptake of new technologies or services may be difficult, delayed or even fail completely if the existing system is 'locked in' at multiple dimensions. In strategic, long-term transport planning this needs to be acknowledged concerning typical transport sector features such as long-span investments and strong role of regulation.

A transport system is a socio-technical system that consists of a cluster of aligned elements: artifacts, knowledge, markets, regulation, cultural meaning, infrastructure, maintenance networks, supply networks, etc. The systemic nature of transport systems together with the grand challenges necessitate new ways of future-oriented system-level thinking, strategic planning and decision-making. There seems to be a lack of sociotechnical foresight methodologies and practical approaches in the transport domain that could dispel the uncertainty and help anticipate future opportunities and threats as a part of the strategic planning process. Instead of using foresight approaches, anticipating the future of transport systems has traditionally focused on analysing and extrapolating past trends and forecasting future trends. Typical example of a well-established futures analysis in the sector is transport volume forecasting. 
In this paper we aim to expand the scientific discussion on the importance of system-level foresight in strategic transport planning. We address the topic through the following research questions:

1. How can socio-technical transitions be anticipated and taken into account in strategic transport planning?

2. What are the techniques to integrate long-term foresight and understanding of socio-technical change to support long-term targets in strategic transport planning?

As our case study, to explore how long-term foresight and transport system visions particularly could be used in anticipating socio-technical changes and consequently supporting strategic transport planning in practice, we use a research project aiming to structure a vision of a safe and secure Finnish transport system in 2100 . The project was launched as a part of the Traffic Safety 2025 research program in 2011.

The paper is structured as follows. First, theoretical approaches relating to long-term foresight and socio-technical transitions in the context of decision- and policy-making are reviewed in Chapter 2. Based on the discussion how they could contribute in the context of transport system and what is lacking in practical methods to be applied in strategic planning, we present a novel approach for combining an analysis of system-level changes and foresight in the transport sector in Chapter 3. We claim that the proposed approach can provide a means to anticipate and take into account sociotechnical transitions in strategic transport planning. This approach extends transport system vision building further to mapping of socio-technical frames for transitions. Chapter 4 demonstrates our case with a vision of a safe and secure Finnish transport system in 2100 , and the key topics in transition are explored and visually illustrated using the developed three-level framework of the transport system. The contribution and practical implications of our novel approach, as well as the outcomes of the demonstration, are discussed in Chapter 5.

\section{Theoretical background}

The theoretical background of the paper stems from integrating insights from two disciplines, long-term foresight and socio-technical transitions, and bringing them into the context of strategic planning and practical decision and policy-making.

\subsection{Long-term foresight}

The impact of foresight on the processes of policy-making has been discussed among foresight experts and practitioners such as Georghiou and Keenan [1], Da Costa et al. [2], Weber et al. [3] and Könnölä et al. [4]. We approach the topic through the three major functions [3] of foresight to support policymaking: 1) informing, 2) facilitation and 3) guiding.

Decision-makers and politicians are dealing with increasingly complex issues that are highly interconnected and multidimensional [2, 4]. Extensive amount of information is available, but the challenge is how to exploit it in the given timescale of policy-making. The informing function of foresight refers to generation of insights regarding the dynamics of change, future challenges and options of steering measures and policies. These new knowledge and ideas are transferred to e.g. policy-makers as an input to policy conceptualization and design [2].

Our approach of modified long-term foresight answers to the informing function raised by the literature by integrating a large amount of future trends and drivers for transport in three levels (landscape, transport system and technologies and services) into a limited set of variables with the help of expert panel and expert workshops.

The second function, facilitation of policy implementation, gets its motivation from the changing nature of policy-making. There has been a shift in the conceptual understanding of policy processes $[3,2]$ from linear to cyclic models of policy-making. The linear model consists of successive phases such as formulation, implementation and evaluation, whereas the cyclic model proposes that the evaluation phase should feed back into the policy formation and implementation phases. In the facilitation function foresight can be seen as an instrument to build common understanding, actor networks and shared visions among stakeholders. It also provides a forum for various actors to communicate, cooperate and learn in relation to a specific change or transition. Foresight processes promote the development of future-oriented attitude among participants, which may ease policy implementation [2].

To respond to the facilitation function, a multitechnological expert group and civil servants from two main transport agencies in Finland were involved in the research. They gave their contributions as work shop participants, commentators as well as disseminators of the results.

The third function, policy guiding, refers to the capacities of foresight to support strategic planning or policy formulation. Weber et al. [3] describe this function as strategic counseling of the policy process. This function occurs only if the foresight process is carried out jointly with the policy-makers in charge of the specific policy field. Foresight exercises may even bring to light the inadequacy of the current policy system to address the major challenges that society is facing [2].

Our case study of safe and secure Finnish transport system 2100 supports the future strategies of transport system safety and security in Finland and hence contributes also to the guiding function. 


\subsection{Socio-technical transitions}

Rotmans et al. [5] have defined transitions as gradual, continuous processes of change, where the structural character of a society transforms. A transition is the result of developments in different domains, and it can be described as a set of connected changes, which reinforce each other but take place in several different areas, such as technology, the economy, institutions, behaviour, culture, ecology and belief systems. Existing systems are often 'locked in' at multiple dimensions, they are stable and not easy to change, and hence new technologies, services or practices are not easily taken up [6]. Instead of comprehensive study of the society, we focus in this paper on one sub-system, the transport system.

To describe changes in socio-technical systems, a distinction can be made between three levels. The socio-technical landscape relates to material and immaterial elements at the macro level: material infrastructure, political culture and coalitions, social values, worldviews and paradigms, the macro economy, demography and the natural environment. The second level, that of regimes (meso level), relates to dominant practices, rules and shared assumptions. At the meso level are the interests, rules, beliefs and organizations that guide private action and public policy. For the most part these are geared towards optimising rather than transforming systems. The niche level (micro level) relates to individual actors and technologies, and local practices. At this level, variations to and deviations from the status quo can occur, such as new techniques, alternative technologies and social practices. The concept of transition can be used at different aggregation levels, such as companies, sectors, countries and regions [5].

System-level changes or transitions have recently been identified as an important area of research in the literature and many related concepts and phenomena are poorly understood [5-9]. In Finland, previous research include some empirical studies in the fields of health care, energy, environment and ICT (information and communications technology) [e.g. $10,11]$, but not in transport, even though transport system can be considered as a model example of a large socio-technical system. Further, tackling grand challenges in the transport sector certainly necessitates transitions in contemporary motor vehicle based, oil dependent transport systems. Consequently understanding of systemic changes needs to be introduced to the context of strategic transport planning. Our paper contributes to these needs by presenting a novel approach for longterm foresight to support socio-technical transitions and related decision- and policy-making.

The LTS (large technological systems) approach developed by Hughes [12] understands technological innovation and stabilisation in terms of systems metaphor. The argument is that those who build technology or technological systems do not concern themselves with (technological) artefacts alone, but must also consider the way in which the artefacts relate to social, economic, political and scientific factors. That is to say, technological systems are open systems and all these factors are interrelated. Among the components of technological systems are physical artefacts, organizations, scientific and legislative components and natural resources. 'System builders' travel between the different domains, such as politics, economics, technology and social change, and weave a 'seamless web' into a functioning whole. According to Hughes [12], the evolvement or expansion of LTS can be presented in the following phases: invention, development, innovation, transfer, growth, competition and consolidation. LTS theory also presents other useful concepts, such as technological momentum (which systems acquire as they mature), technological style, and reverse salient, that can help in discovering or understanding new aspects in technological development.

The SCOT (social construction of technology) approach [13] is a complementary approach to the LTS theory. In this constructivist study of technology, technological stabilisation is referred as 'closure' concept and presented as follows: 'When the social groups involved in designing and using technology decide that a problem is solved, they stabilise or consolidate the technology. The result is closure. Various groups will, however, decide differently not only about the definition of the problem but also about the achievement of closure and stabilisation'.

The above theoretical approaches suggest that system-level changes, technological stabilisation being part of it, can be understood only if the technological aspects are seen as being interrelated with a wide range of non-technological factors. The approaches present good theoretical considerations on analysis of the past, but it seems that practical methods having future orientation and to be applied in strategic planning and are lacking. In addition, as we have already recognized from the practical side, tackling the grand challenges in the transport sector necessitates systemic changes, which again require practical approaches and tools to be introduced in strategic planning and decision-making processes.

In this paper, we use the term "foresight", as it is used in the field of futures studies, to describe activities such as: 1) critical thinking concerning long-term developments, 2) debate and effort to create wider participatory democracy and 3) shaping the future, especially by influencing public policy. Foresight encompasses a range of approaches, e.g. scenario building and Delphi method that combine the three aforementioned activities. Foresight is particularly a strategic decision-making tool, which helps a company, organization, or even a whole sector of society to respond to the question of how we can succeed in a changing world. Public participation in transport plans is an example of short term transport foresight, which has encouraged wide interest and debate for decades. There are, however, some examples of longer term participation exercises and the importance of co-operation and partnerships in future transport systems [e.g. 14-16]. 
In the following section, we present a novel approach for combining an analysis of system-level changes and foresight in the transport sector. We claim that this kind of approach can provide a one possibility to anticipate and take into account socio-technical transitions in strategic transport planning.

\section{Novel approach to transport foresight}

\subsection{Transport system}

A transport system is a large socio-technical system, where transport services are provided by employing a variety of technologies and solutions. Technological, social, economic, political, legal and environmental dimensions are all immanent, and the interaction of these dimensions with one another contributes to the complexity of the functioning of a transport system. The three basic components of the transport system are transport infrastructure, vehicles and users. In addition, a fourth, managerial component can be identified to account for transport system governance and regulation. Each of these components functions and influences one another in the aforementioned six dimensions.

On the other hand a transport system as a whole can be perceived as one component in the wider societal landscape. From this point of view transport is an enabler, providing mobility in the society. The transport system is affected by e.g. energy systems and social structures. Transport services are created using resources and technologies from a multitude of application areas. We propose that socio-technological changes and transition processes in the transport system can be explored using a three-level framework. The three levels inspired by Geels [17] and further adapted to the context of transport are from the most aggregated to the most detailed:

- Level A. Landscape

- Level B. Transport system

- Level C. Technologies and solutions.

The three components that build up the transport system (users, infrastructure and vehicles), as well as the fourth component for transport system governance and regulation, are mapped in Fig. 1 on the three-level framework. The position of each component indicates the most relevant level or levels where activities take place. However, all four components function in interaction with one another across all three levels. In addition, in Fig. 1 some key elements relevant to each of the transport system components are illustrated, positioned to indicate their main application level.

\subsection{Vision building process}

In order to anticipate potential transport system futures, a vision building process has been developed [18]. The process consists of three consecutive steps (Fig. 2), where appropriate futures techniques are used to involve transport sector experts and formulate one or several images of the future transport system. Suitable time frame ranges from 50 to 100 years into the future. The three steps of the vision building process are: 1) environmental scanning, 2) futures table and visions and 3) describing visions.

The first step, environmental scanning, is a survey of forces of change, where trends and signals to impact the transport system and the entire society in the selected time frame. Literature research and expert workshops serve as input for this step, and the list of forces of change can be organised using PESTE (political, economic, social, technological and environmental) analysis and transition management. Relevant transport sector experts to be involved include policy-makers, authorities and academics. The outcome of the first step is a list of forces of change organised on the following levels: 1) landscape, 2) transport system with subdivision into political, economic, social and environmental factors and 3) technologies and solutions.

The core of the second step, futures tables and visions, is to arrange a futures workshop where relevant transport system stakeholder groups take part in the envisioning process. Before the workshop, the list of forces of change compiled in the first step needs to be reduced to a compact list of 10 to 20 topics by an expert panel. Selected forces of change will serve as variables in the futures table, and three to six alternative futures will be generated to describe each variable. To fill up the futures table by formulating the alternative futures is the first task in the futures workshop for transport sector experts. The second task is to discuss and choose a starting point and a path for the vision. The starting point could be e.g. an entry in the futures table or a predefined goal that motivated the vision building exercise in the first place. The vision path is then formulated by selecting a suitable alternative future describing each variable to define the vision. According to the objectives of the envisioning process, the participants of the workshop could be encouraged to find a consistent, mutually agreed transport system vision or a set of alternative visions. The line-up of the workshop may include e.g. policy-makers, authorities, academics, organizations, companies and citizens. Wide representation of relevant actors and fields is essential, and ideally the list of invitees could be an extension of the expert workshop from the first step of the vision building process. The second phase futures workshop would thus involve both the already committed transport sector experts and the newly invited stakeholders from a more diverse background. 
Fig. 1 The three-level framework to study the transport system

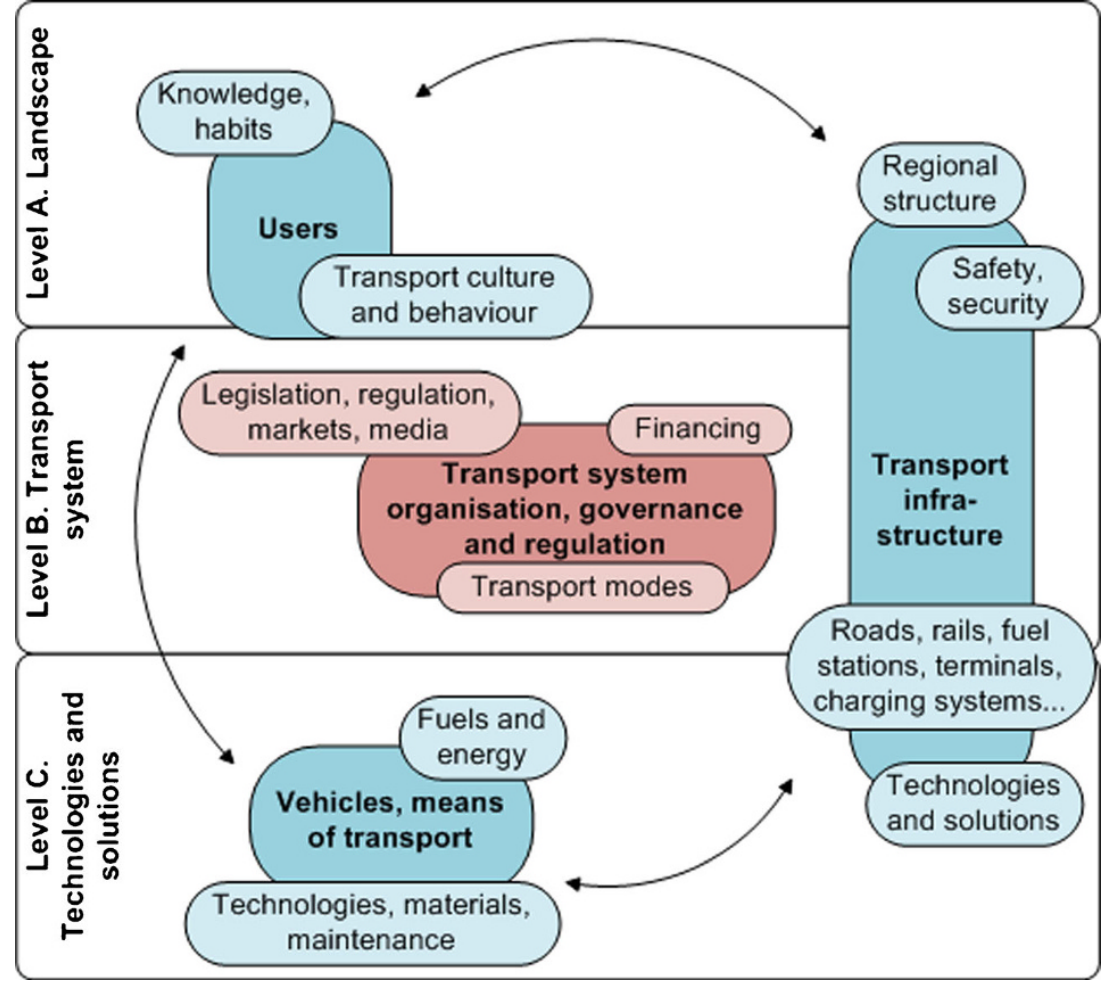

The third and final step, describing visions, brings the vision or visions into life: a manuscript is created for each vision, based on the vision paths sketched in the futures table. Besides written reporting, useful approaches to describe and explain a vision include visual illustrations, time lines, short stories and mind maps. Six relevant themes in the context of transport systems to be covered are 1) society as whole, 2) energy system, 3) transport system, 4) transport system technologies and services, 5) transport safety and security and 6) transport and environment.

In this paper, we elaborate the vision building process further, and the three-level framework of the transport system (Fig. 1) will be linked into it. When combined, vision building and mapping of socio-technical frames for transitions enable a thorough exploration of analysing socio-technical change in the transport system.

\section{Envisioning a safe and secure transport system}

\subsection{Background}

In order to explore how long-term foresight and transport system visions particularly could be used in anticipating socio-technical changes and consequently supporting strategic transport planning in practice, research study aiming to structure a vision of a safe and secure Finnish transport system in 2100 was launched as a part of the Traffic Safety 2025 research program in 2011. The study built on previous work within the research programme, where the method vision building process [18] had been structured. The objective of the study was to outline one possible image of the future transport system in Finland that would fulfil the ambitious traffic safety goals as expanded from the nationally established short- to mid-term road safety targets. These goals pursued a vision of a safe and secure transport system where no serious accidents leading to injuries, fatalities or damage to property or the environment occur.

\subsection{Process}

\subsubsection{Vision building}

The working process to create the vision was organised according to the vision building process with minor adjustments [18]. Futures literature on transport but also other sectors and aspect in the society was scanned. Topics of special interest were safety and security, energy systems, innovation in ICTs and societal developments.

Two futures workshops were organised, and transport sector experts to take part in these two events were selected by personal invitations. The selection principle for participants was that the combined know-how in each workshop would cover all transport modes as well as a maximum variety of transport-related topics such as environment, fuels, energy, safety, passenger transport, public transport, freight logistics, ICTs and transport policy. For the first workshop (step 1, environmental scanning) participants consisted of ten 
Fig. 2 The three-step vision building process to create transport system visions
3. Describing visions

Objective: to create a manuscript for each vision and to explore alternative development paths.

Methods and tools: written and visual illustrations and transition management.

Result: description of each vision and alternative development paths.

\section{Futures table and visions}

\section{Objective: to build a table of alternative images} of the future (futures table), to formulate a starting point and a path in the table for each vision.

Methods and tools: futures table, expert panel and expert workshop.

Result: futures table and vision paths.

\section{Environmental scanning}

Objective: to map and structure relevant forces of change on three levels: landscape, transport system and technologies and solutions.

Methods and tools: literature survey, exper workshop, PESTE analysis and transition management.

Result: list of forces of change. researchers of different fields within transport safety, shipping, logistics, transport economics, intelligent transport systems (ITS), human technology interaction (HTI), daily mobility and low carbon energy for transport. The rationale for inviting researchers only was that they would provide the best knowledge of past, current and future trends within their area of expertise. This allowed the structuring of a comprehensive list of forces of change based on researchers' views that was further on validated and amended by the more heterogeneous line-up for the second workshop.

The second expert workshop (step 2, futures tables and visions) involved representatives from national transport and transport safety agencies as well as researches. The objective was to actively involve transport authorities, i.e. the stakeholders in charge of strategic and operative aspects in decision-making. The mixed approach brought together the expertise and future views of ten academics and practicing transport authorities, thus ensuring a sound theoretical as well as practical basis for the vision. As a result of the workshop, the key variables and starting points for vision building were defined. Low carbon energy for transport as the environmental philosophy and automation and intelligent solutions were identified as the two starting points. These two topics manifested themselves throughout the expert workshop, both in terms of setting boundary conditions to the vision and in terms of providing opportunities and solutions to reaching the envisioned safety goals. Next, the manuscript for the vision was structured to analyse five of the predefined six themes suggested by the vision building process. Transport safety and security as a separate theme was omitted, as it was elevated to the centre of focus within the other five themes. The vision is summarized in Section 4.3.

\subsubsection{Mapping socio-technical frames for transitions}

Having formulated the vision, the most important forces of change resulting in socio-technical transitions, as identified in the literature and the futures workshops, were mapped on the three levels (landscape level, transport system level and level of technologies and services) relevant in the context of transport systems. Next, we used the three-level framework of the transport system to illustrate the two key topics that together with the transport safety targets laid the foundations for the vision of a safe and secure Finnish transport system 2100 . As concluded in the future workshops, the two key topics that characterized the experts' discourse dealt with environmental philosophy and automation and intelligent solutions. Issues related to these two topics were continuously being referred to during the workshops. Environmental challenges and possibilities with automation and other intelligent applications were depicted by the experts as boundary conditions to the vision, complementing the safety goals. Secondly they were 
perceived as key areas where synergies of interests as well as technological solutions to reach the envisioned future of a safe and secure transport system could be found. Consequently, these topics were justified selections for the illustrations. In addition, we present a third complementary illustration, where the networks of actors within the envisioned transport system are explored. This third topic was chosen to highlight the importance of cooperation between the transport system stakeholders as perceived by the workshop participants: i.e. commitment of stakeholders from different fields and backgrounds to cooperate towards the safety goals and also recognition of changing dynamics among the stakeholder groups.

The illustrations show the main elements and their linkages within each of the topics. This contributes to the identification of transitions of different type and size that play a role in reaching the vision. Interactions between developments and how they can build up to enable major transitions can be analysed. Further, they can support strategy and policy design and decision-making with the aim to initiate, encourage or accelerate desired transitions on a desired development path towards the vision. On the other hand, the illustrations could be used as a tool to identify potential risks and obstacles. The illustrations of the key topics are presented in Section 4.4.

\subsection{Vision}

The vision of a safe and secure Finnish transport system in 2100, where no serious accidents leading to injuries, fatalities or damage to property or the environment occur, was formulated based on two central base assumptions as shaped in the futures workshop. Firstly, sustainable and carbon neutral energy production was brought up as a defining characteristic of the electricity intensive society. Secondly, wide use of automated and intelligent applications in various technology fields was selected as the enabler of safety and security.

The Finnish society was assumed to follow a fairly unsurprising development path with moderate growth in population and economy and advancement in technologies. In the energy sector, a separation from fossil fuels was anticipated. The main sources in electricity production in the vision are biomass, hydro power and nuclear energy, each accountable for a quarter of the total electricity mix.

The dominant mode in the envisioned transport system is rail. Half of all passenger transport and about two thirds of freight movements use the extensive rail network. Fast rail transport connects cities, and urban rail systems, the vehicles of which are able to separate as small modules from the rail network to move on the street infrastructure, cover the densely populated areas. Pedestrian traffic and cycling have improved their standing in personal mobility, and the safe transport environment combined to easy spatial accessibility make them the most attractive choice for most uses in the urban environment. The complementary mode for both passenger and freight transport outside the rail network is road. Air transport has a marginal role in long distance travelling and sea transport is solely used for long distance shipping. All motorized transport is powered with electricity and operated in full automation.

The physical and service infrastructures of the envisioned society do not limit to sectoral applications, but e.g. transport functions as one part of the integrated infrastructure system. Transport services are managed in this shared multi-service environment, and synergies with other applications contribute to e.g. transport safety, mobility planning services and logistics efficiency. Risks and uncertainties regarding the reliability and undisturbed operation of the transport system culminate to the dependence on automation and intelligent systems. However, challenges regarding these issues were considered to have been solved by 2100 , when the integration of transport systems among other applications was depicted as stable and well established. Environmental risks and impacts of the envisioned transport system are negligible; vehicle operation and electricity production release no harmful emissions, and use of materials in physical structures complies with sustainable practices.

The roles of public authorities and private companies are re-organised in the vision, and provision of transport services as well as upkeep, operation and maintenance of the transport system are managed by a new type of network. Authorities, businesses and citizens all interact in this network, enabling real-time information exchange and efficient operation.

\subsection{Socio-technical transitions}

\subsubsection{Forces of change}

Figure 3 shows the most important forces of change behind the socio-technical transition leading to the envisioned safe and secure transport system in 2100 . These forces of change and resulting changes are mapped on three levels (vertically): landscape, transport system and technologies and solutions. They are also organised in three successive phases (horizontally): emergence, diffusion and establishment. The idea to seek for time-dependent sketching of the developments along the vision path has been adapted from studies by Geels $[6,15]$, but it corresponds also to the idea of evolution of large technological systems and the concept of technological momentum by Hughes [13]. Furthermore, Fig. 3 shows elements that are strong drivers with major impact (colored background) but also weak or dying innovations that may at first seem promising but gain only little impact in the long run. Key relationships between forces of change on different levels and how drivers from levels $\mathrm{A}$ and $\mathrm{C}$ give momentum to changes on level $\mathrm{B}$ are indicated with arrows. Figure 3 provides the wider context for the more detailed illustrations presented in the following Sections. 


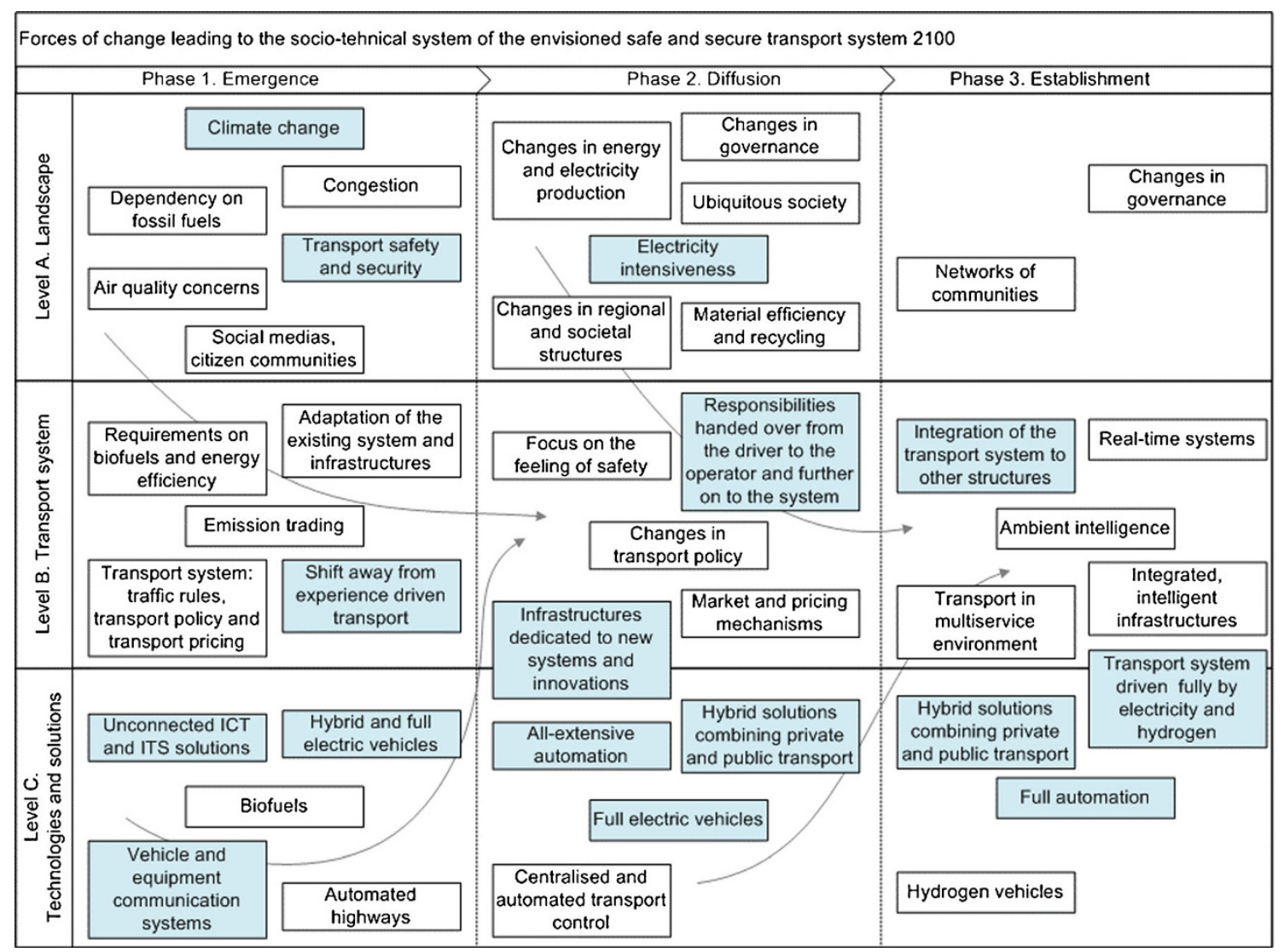

Fig. 3 Forces of change leading to the establishment of the new socio-technical system of the envisioned safe and secure transport system

\subsubsection{Environmental philosophy}

Figure 4 illustrates the most important elements within the topic of environmental philosophy. The initial driving forces towards the very ambitious vision of a sustainable and carbon neutral energy production in an electricity intensive society can be identified on levels A and B, the landscape and transport system-levels.

Interest from the user side in a clean transport environment as well as political consensus over issues dealing with energy and the environment are here the key. Commonly accepted value base enables focused decision-making towards an environment friendly transport system, in this case realised by means of electrification. Efforts from the transport system organisation, governance and operation have been directed to support carbon neutral energy production and smart electricity grids that are required in order to have a functional electrically driven vehicle fleet. Technical specifications, standardisation and labelling are examples of tools that may be used to reach the desired impacts in technology development in the means of transport as well as transport infrastructure. Solutions for vehicle technologies, batteries and charging infrastructure can benefit from such activities. The uniform value base is also manifested through responsible customer choices made by the users of the transport system. This shows e.g. in preference to choose emission-free and silent electric transport and appreciation for sustainable use of resources. On the other hand regulative or economic measures to steer the development in the desired direction were not discussed in the workshops in detail.

\subsubsection{Automation and intelligent solutions}

Figure 5 illustrates the most important elements within the topic of automation and intelligent solutions. For this topic the sparks to ignite and accelerate uptake of automation and other technological innovations can emerge on any of the three levels, and the pathways towards the envisioned state of fully automated motorized transport with variety of intelligent applications ensuring safety and security can be very complex. Supposedly parallel but interlinked evolution processes are required most importantly in the technology development around vehicles, vehicle materials and structures, transport infrastructures with large information flows and integration to other systems. But similar evolution processes are also required in business models and multi-service environments that accommodate and diffuse the more technology-oriented elements. All of the aforementioned aspects benefit from technical specification, standardisation and other supporting measures that may be introduced by the transport 
Fig. 4 'Environmental philosophy' on the three-level transport system framework

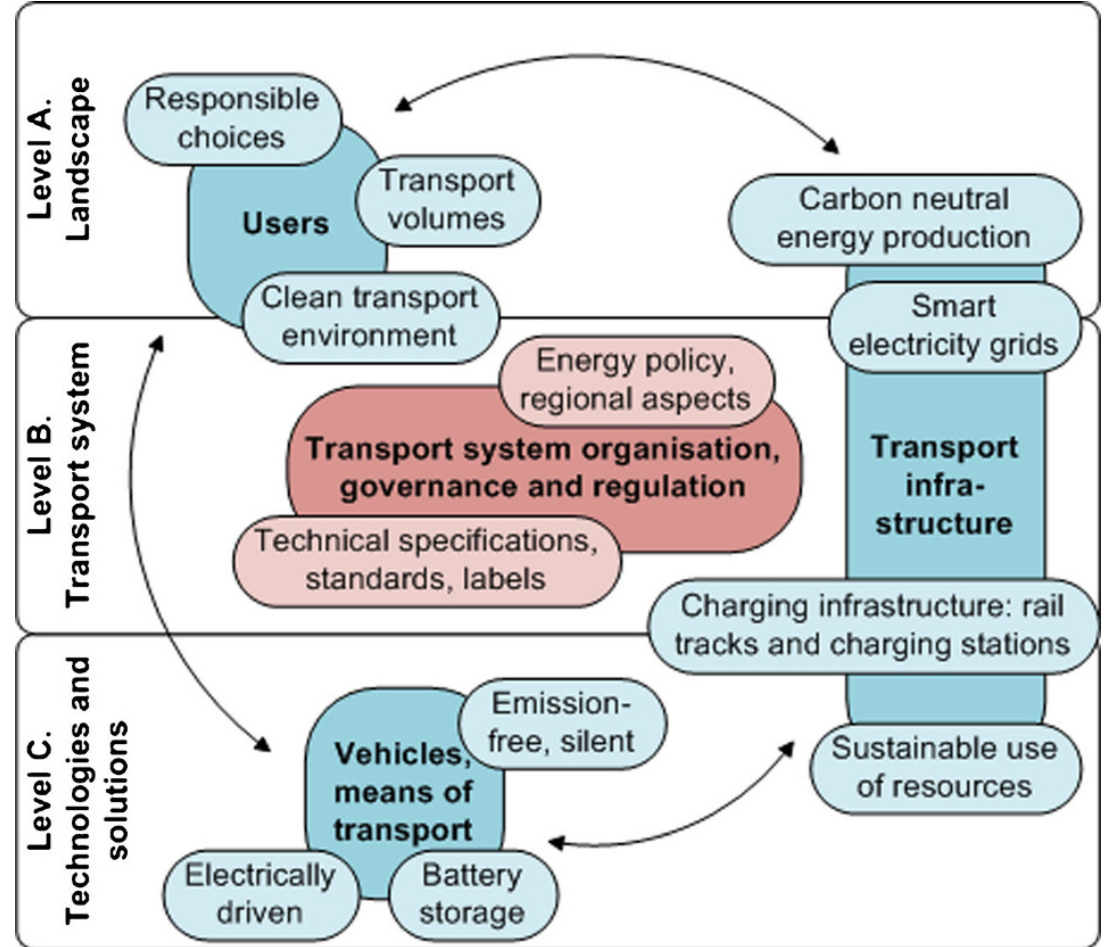

organisation, governance and regulation on the transport system level. On the other hand, implementation of complex and advanced technologies with diverse impacts and risks have to be introduced in a controlled way, and monitoring and sets of requirements on reliability, safety and security need to be paid attention to on the transport system level.

Wide deployment of automation and advanced intelligent technologies necessitates pull mechanisms and acceptance from the user side. Positive incentive to adopt these new concepts include, besides the targeted safety and security improvements, smooth traffic flows, more flexibility in how travel time and in-vehicle space can be used and easy multiservice solutions for e.g. travel planning. More controversial issues are the absence of driving experience and vehicle ownership that may be welcome news for some user groups but more difficult to accept by others. Implementation of various policy instruments may be required in addition to introduction of attractive new choices, such as automation and public domain or shared vehicles. Here new ways of strong governance is needed in policy implementation and in identification of roles and building co-operation between public and private bodies.

\subsubsection{Networks of actors}

Figure 6 illustrates the most important elements within the topic of networks of actors. This is a very large topic with multiple dimensions but very little organised structure in the vision of the safe and secure transport system. However, because of the major importance of the topic, a few aspects raised along the futures workshops are addressed.

The dominant view was that the different user groups of the transport system will have a more active role in the planning and management processes linked to the transport system. Roles among users and the public and private sectors would thus be organised in a new balance, where many tasks are divided between these three actor networks. The main responsibilities in transport system organisation, governance and regulation, e.g. monitoring and controlling measures, would still be in the hands of authorities and service businesses, but with extensive involvement of the users.

One dimension that involves all the networks of actors within the transport system is the information flow. Manufacturing industry bringing vehicles to market has the key role in issues dealing with vehicle-born information. Other manufacturing and service businesses take interest in the infrastructure-born information in the context of the transport system. Transport system organisation and governance needs the information flows from these two sources and at the same time it has a role to play in organising a general environment where information can be created, shared and made use of in a safe, secure and efficient way. The users can also be seen as the ones creating the vehicle-born, infrastructure-born and other information in real-time. And the users are the ones that ultimately get the benefit that may manifest itself as e.g. advanced travel planning solutions and most importantly as provision of transport services that answer the transport patterns and transport demand expressed by the users. 
Fig. 5 'Automation and intelligent solutions' on the threelevel transport system framework

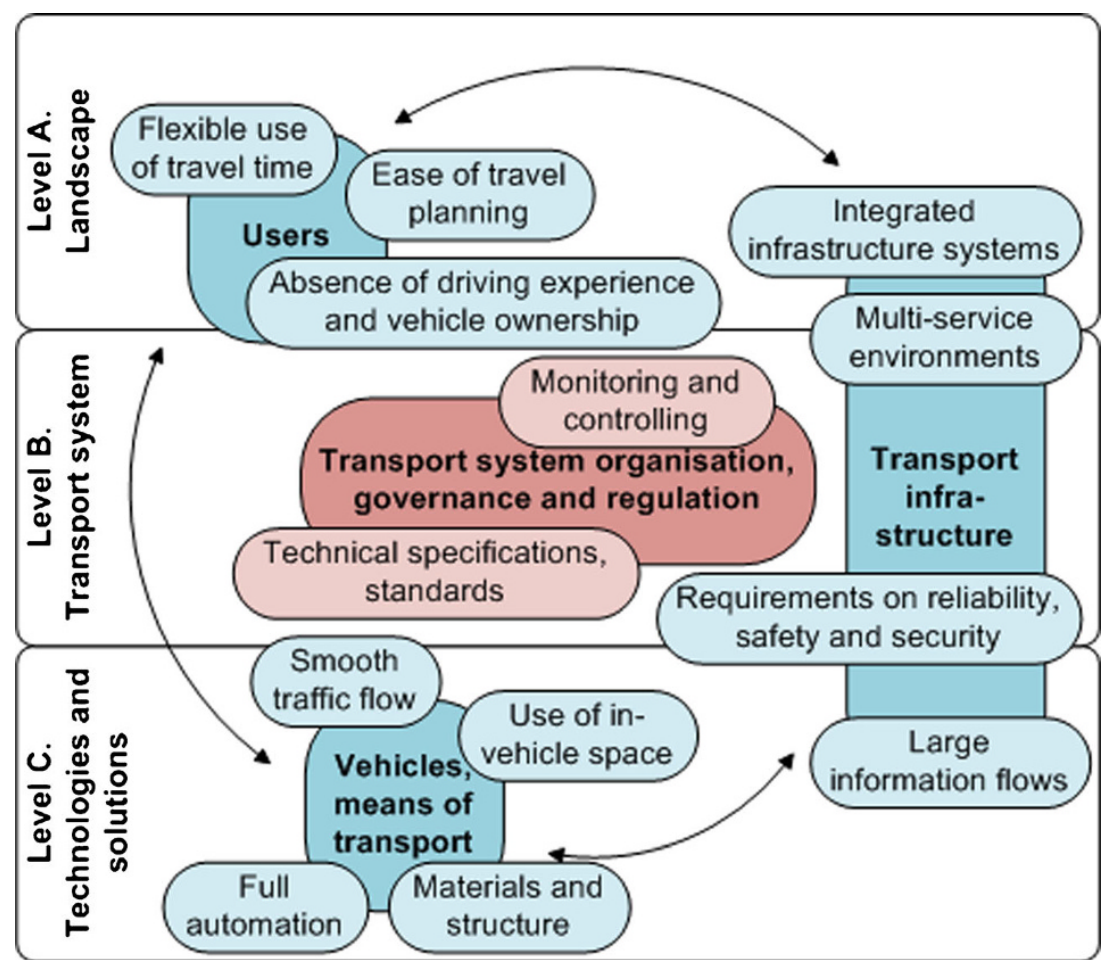

\subsubsection{Integration of the key topics}

Each of the three topics presented above provide an important viewpoint on the future components of the safe and secure Finnish transport system in 2100 . When brought together into a systemic view, future challenges and opportunities of the transport system as a whole can be identified and key policy measures towards identified vision recognized.

As regards the infrastructure component of the transport system, the main challenges relate to construction and management of smart, user friendly transport corridors in which ICT, smart energy, urban planning and service structures are
Fig. 6 'Networks of actors' on the three-level transport system framework

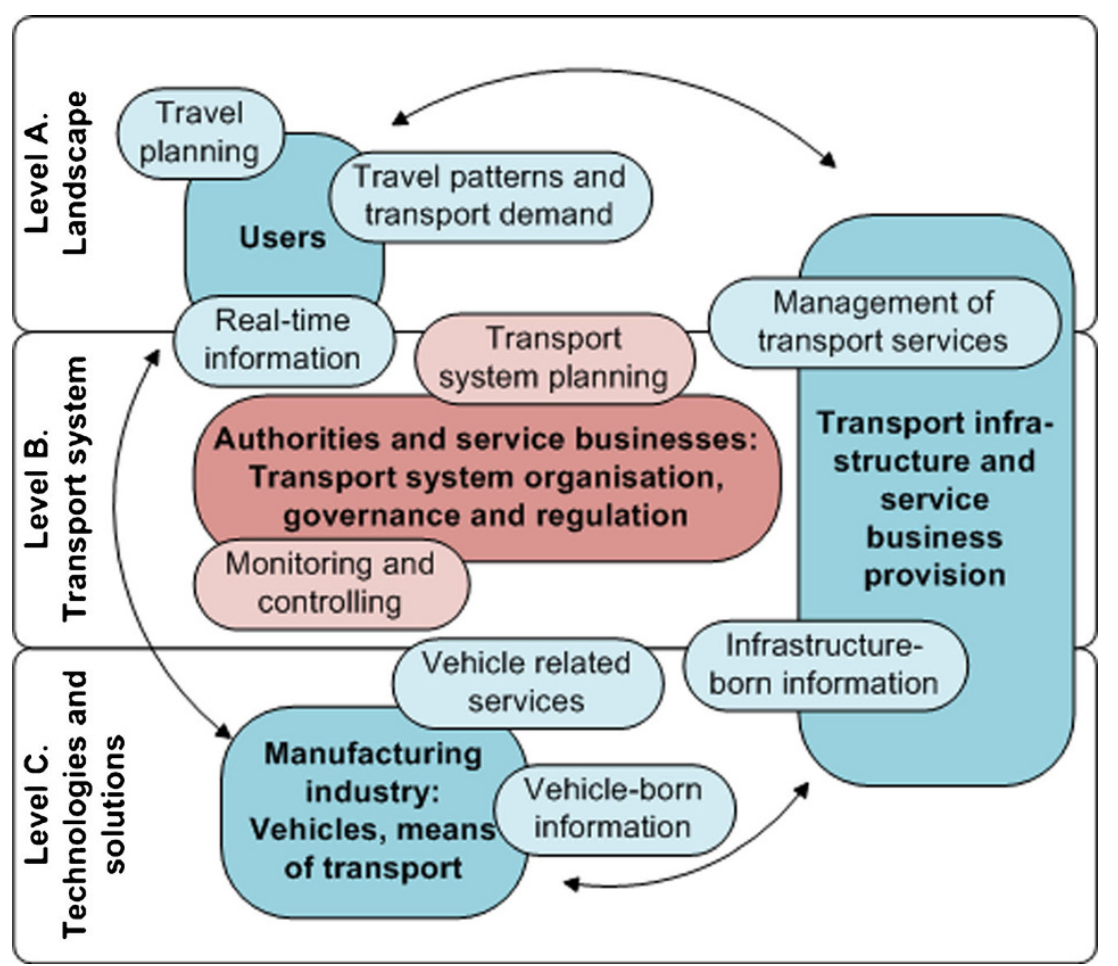


integrated. Combining intelligent transport technologies and services (ITS) and electro mobility targets provides the main challenge for vehicle component. Linking multi-level monitoring and controlling into the processes of strategic planning are issues which need careful consideration within the governance \& regulation component. Finally, how to provide ease of travel in an environmentally friendly (carbon free) transport system accompanied with a notable amount of travel substitution seems to be the critical questions of the future from the point of view of transport system end users.

\section{Discussion and conclusions}

In this paper we explored long-term, system-level foresight in the context of transport systems through two research question. The first question on how socio-technical transitions can be anticipated and taken into account in strategic transport planning was addressed by an outlook on several theoretical approaches. The conclusion was that practical methods to apply foresight to future-oriented long-term strategic planning are currently lacking. To answer this research need, we presented a novel approach, the three-level framework for the transport system (Fig. 1), that together with long-term visioning wraps up the theoretical foundations to support the analysis of socio-technical transitions in the transport domain. Our approach expands the application area of analysis of sociotechnical change from the past also to the future-oriented strategic planning and policy support.

The second research question inquired after the techniques to integrate long-term foresight and understanding of sociotechnical change to support long-term targets in strategic transport planning. We answered this by extending our proposal of the novel approach to practical tools. We demonstrated our case with a vision of a safe and secure Finnish transport system in 2100 by using a structured vision building process. Furthermore, techniques to identify and analyse the sociotechnical changes and transition process as prerequisites to the envisioned transport system to actualise were introduced. The proposed approach contributes to all of the three functions of foresight in policy-making presented in Section 2. An interesting notion relevant to the transport system is that socio-technical change may initiate either from within the system or from external structures linked to it. The latter may appear e.g. as developments resulting from the level of specific technologies and solutions or as landscape level pressure, such as the transport safety and security aspirations in our demonstration. The approach we propose pursues on the one hand to identify and address any forces of change that may drive the evolution of the transport system. On the other hand it provides the means to generate momentum towards desired future directions.
An important part of the demonstration was to show how visual illustrations using the three-level framework of the transport system function as a tool to explore identified key topics in the transition towards the vision. The illustrations highlight the key elements and their linkages to be considered in socio-technical change towards the vision. Such key topics in the vision created for the safe and secure Finnish transport system in 2100 were environmental philosophy, automation and intelligent solutions and networks of actors.

Our demonstration with the case study proved our approach applicable and useful. It is simple enough to be applied also in other countries and regions. The approach produces new information on how to use and combine methods from various disciplines. It also facilitates mutual learning on how to overcome certain barriers. The proposed approach contributes to the identification of socio-technical changes of different type and size that play a role in reaching the desired vision. The interactions between the components and elements of future transport systems and related opportunities and potential risks can be identified and analysed. Further, interactions between developments and how they can build up to enable major transitions can be studied. The approach can support strategic planning and decision-making by bringing together various transport system actors to discuss the potential future developments and by showing, based on the discussions, the shared key development areas, challenges and policy instruments to encourage or accelerate desired changes on a desired development path towards the vision. The proposed approach can actually be seen as a policy instrument by definition.

The vision of the safe and secure Finnish transport system in 2100 has already contributed to more future-oriented discussions on the national transport system and its connections to the European and global transport networks. Long-term considerations have raised questions such as what are the technical implications if a high-speed rail network was to be the primary transport mode both in domestic and international transport. It has been argued that the vision itself is fairly conservative, but even as such it prerequisites several significant changes that in turn would require decision-makers and other stakeholders to activate right now e.g. by starting the required changes in the organization of the transport sector or in transport networks. In the following we list further examples of possible application areas where the approach presented in this paper could be adopted. Areas where our approach has already been given the first introduction in or where elements similar to those within it have been put to use are marked with asterisks. The proposed techniques could facilitate and initiate actions and decisions to:

- $\quad$ support long-span urban and regional planning*

- discover potential in replacing conventional vehicles with e.g. electric propulsion technologies*

- design innovative mobility visions for pedestrian and bicycle transport* 
- $\quad$ anticipate requirements for transport infrastructure based on anticipated changes in transport and mobility

- find shared research priorities within large, branched research programs*

- build stakeholder coalitions to promote alternative vehicles and fuels*

- draft how roles and responsibilities of the changing stakeholder ecosystem could be re-organised.

Furthermore, an important contribution of presenting a vision, such as that of a safe and secure Finnish transport system in 2100, is that even if the envisioned future state is not agreed on, it helps the decision-makers to focus on the long-term issues and to realize the importance and potential of participatory future oriented strategic planning.

Acknowledgements This research was supported by research programme Traffic Safety 2025 (http://www.vtt.fi/proj/tl2025). The authors wish to extend special thanks to programme coordinator Juha Luoma (VTT), colleague Toni Ahlqvist (VTT) and all workshop participants.

Open Access This article is distributed under the terms of the Creative Commons Attribution License which permits any use, distribution, and reproduction in any medium, provided the original author(s) and the source are credited.

\section{References}

1. Georghiou L, Keenan M (2006) Evaluation of national foresight activities: assessing rationale, process and impact. Technol Forecast Soc Chang 73(7):761-777

2. Da Costa O, Warnke P, Cagnin C, Scapolo F (2008) The impact of foresight on policy-making: insights from the FORLEARN mutual learning process. Tech Anal Strat Manag 20(3):369-387

3. Weber M, Kubeczko K, Kaufmann A, Grunewald B (2009) Tradeoffs between policy impacts of future-oriented analysis: experiences from the innovation policy foresight and strategy process of the city of Vienna. Tech Anal Strat Manag 21(8):953-969

4. Könnölä T, Scapolo F, Desruelle P, Mu R (2011) Foresight tackling societal challenges: impacts and implications on policy-making. Futures 43(3):252-264
5. Rotmans J, Kemp R, van Asselt M (2001) More evolution than revolution: transition management in public policy. Foresight 3(1):15-31

6. Geels FW (2005) Processes and patterns in transitions and system innovations: refining the co-evolutionary multi-level perspective. Technol Forecast Soc Chang 72(6):681-696

7. de Haan JH, Rotmans J (2011) Patterns in transitions: understanding complex chains of change. Technol Forecast Soc Chang 78(1): 90-102

8. Elzen B, Wieczorek A (2005) Transitions towards sustainability through system innovation. Technol Forecast Soc Chang 72(6): 651-661

9. Geels FW (2004) From sectoral systems of innovation to socio-technical systems: insights about dynamics and change from sociology and institutional theory. Res Policy 33(6-7): 897-920

10. Kivisaari S, Kokkinen L, lehto J, Saari E (2009) Management of system innovation in welfare and health sector. Lessons learned from two case studies [Sosiaali- ja terveydenhuollon systeemisen innovaation johtaminen kahden tapaustutkimuksen opetuksia]. VTT Res Notes 2504

11. Heiskanen E, Kivisaari S, Lovio R, Mickwitz P (2009) Designed to travel? Transition management encounters environmental and innovation policy histories in Finland. Policy Sci 42:409-427

12. Hughes TP (1987) The evolution of large technological systems. In: Bijker WE, Hughes TP, Pinch T (eds) The social construction of technological systems. New directions in the sociology and history of technology. MIT Press, Cambridge, pp 51-82

13. Pinch TJ, Bijker WE (1987) The social construction of facts and artefacts: or how the sociology of science and the sociology of technology might benefit each other. In: Bijker WE, Hughes TP, Pinch T (eds) The social construction of technological systems. New directions in the sociology and history of technology. MIT Press, Cambridge, pp 17-50

14. Burbidge TK, Knowlton T, Matheson A (2007) Wasatch choices 2040. A new paradigm for public involvement and scenario development in transportation planning. Transp Res Rec 1994:147-153

15. Waskowiak P, Garber K, Durham C (2007) Envision Houston region. Shaping the future together in Texas. Transp Res Rec 1994:154-158

16. Toleman R, Rose G (2008) Partnerships for progress. Toward sustainable road system. Transp Res Rec 2067:155-163

17. Geels FW (2002) Technological transitions as evolutionary reconfiguration processes: a multi-level perspective and a case-study. Res Policy 31(8-9):1257-1274

18. Auvinen H, Tuominen A, Ahlqvist T (2012) Towards long-term foresight for transport: envisioning the Finnish transport system in 2100. Foresight 14(3):191-206 